\title{
Formas de habitar
}

\section{FELIPE CORVALÁN TAPIA}

Editor Revista de Arquitectura

Facultad de Arquitectura y Urbanismo

Universidad de Chile
Refiriéndose al título de su última publicación, Tema Libre (2018), el escritor chileno Alejandro

Zambra recuerda aquel momento de la vida escolar en el que el profesor, a medio camino entre el agotamiento y las últimas reservas de ilusión, decide dar carta blanca a sus estudiantes renunciando a la imposición temática. Coincidiendo con el título de Zambra, por primera vez la convocatoria de Revista de Arquitectura no incluyó en su llamamiento un ámbito de reflexión específico. En nuestro caso, el motivo no está relacionado con la decepción por los resultados anteriores, más bien con un reconocimiento explícito a la heterogeneidad de enfoques presentes en los trabajos que número a número llegan hasta nuestra bandeja de entrada.

El resultado del experimento es diverso, pero creemos que igualmente coherente, pues desde distintas miradas cada uno de los artículos aquí reunidos vuelve sobre un asunto sustancial de la condición humana y por tanto también de la propia arquitectura: el habitar y sus variadas formas de expresión. De esta manera, el inicial tema libre se ha convertido en un tema recurrente, en un espacio de interés general y esencial para pensar la arquitectura, pero no acotado "en" ella ni "por" ella. Así, sin la pretensión de definir un término lo suficientemente complejo para establecer sentencias, planteamos en esta edición una aproximación contemporánea al habitar, sin por ello dejar de dialogar con la historia o la tradición.

En esta oportunidad, abren la sección de artículos tres trabajos que a partir del análisis programático reflexionan sobre condiciones de habitabilidad específicas. En el primero de ellos, "Ambientes favorables para la salud. Un legado intergeneracional en el paisaje urbano", Gabriela Campari indaga sobre los beneficios de la presencia de áreas verdes en la infraestructura hospitalaria, más concretamente en la tipología de hospital de pabellones. De acuerdo a la autora, esta inclusión de zonas verdes es altamente positiva para la comunidad que habita estos edificios, mejorando sustancialmente sus condiciones ambientales.

Posteriormente, la investigación "Plan de fomento del alojamiento de Sevilla, 1929: El Hotel América Palace, un diseño adaptativo" de Vicente Flores-Alés, Reyes Abad, Isidro Cortés y José María Calama centra su atención en la innovación y versatilidad del edificio proyectado por el arquitecto Fernando Guerrero Strachan. Una obra capaz de transitar sin problemas desde su primera condición de hotel hacia su conversión en espacio de viviendas.

En el caso del texto "The Polyvalent Forms of the Galata Bridge" Esen Gökçe Özdamar nos propone ampliar las consideraciones exclusivamente programáticas sobre el Puente Gálata de la ciudad de Estambul. Para la autora, no solo se trata de un espacio que permite transitar de un lugar a otro, pues en él convergen, se superponen, diversas e intensas relaciones sociales, cuestión que le otorga al puente un innegable valor cultural. 
De las particularidades de Estambul viajamos hacia Santiago de Chile, a través de dos trabajos que abordan el problema de la vivienda como asunto fundamental del habitar contemporáneo, constituyendo una segunda estación en la línea argumental de este número de la revista. A través del seguimiento de debates sostenidos en prensa y redes sociales, "Arquitectura y densidad. Controversias en torno a los edificios en altura. El caso de Santiago de Chile" de Jorge Vergara y Diego Asenjo pone el foco sobre la vivienda en altura y sus efectos, una tipología ampliamente utilizada en el proceso de repoblación de la ciudad de Santiago.

Por su parte, "Barreras legales de acceso a la vivienda social en la comuna de Santiago" de Michelle Cáceres presta atención a los mecanismos de acceso a la vivienda y a las restricciones que presentan las políticas de financiamiento impulsadas por el Estado. Más allá de los logros cuantitativos, la autora se refiere a deficiencias cualitativas aún pendientes.

En la última parte de la sección de artículos nos encontramos con un acercamiento, desde perspectivas distintas, a la relación entre habitar, patrimonio y prácticas culturales, tradicionales y también contemporáneas. "La organización del espacio doméstico en la arquitectura vernácula de San Pedro de Atacama. Relaciones sintácticas en la construcción del espacio patrimonial" de Víctor Rojas, expone formas de organización espacial fuertemente arraigadas. La valoración realizada por el autor considera aspectos tangibles e intangibles de esta particular forma de habitar, convertida en ideario colectivo.

En cuanto al texto de Omar Cañete, "Mecanismos de reificación sociourbana del muralismo en Valparaíso. Lo onírico-grotesco como estética predominante actual", este elabora un marco teórico que permite pensar el alcance de rayados y grafitis que hoy abundan en la ciudad, cuyo examen no siempre es posible a partir de parámetros estéticos habitualmente utilizados.

En la habitual sección reflexión estudiantil, el proyecto "Todo es cancha'. Borde de equipamiento recreativo vecinal" de Sebastián Simonetti reconoce en la arquitectura la capacidad de activar el espacio cotidiano, prestando atención a las formas de asociación desarrolladas por la comunidad. A través del fútbol como programa colectivo y aglutinador, la intervención incorpora los ritos preexistentes del barrio, al tiempo que ofrece una respuesta contemporánea.

Por último, en nuestro también habitual espacio de reseñas, Luis Silva recupera el libro "Memorias de un arquitecto obstinado" de Miguel Lawner. Un texto publicado el año 2013, pero que hoy, debido a la reciente obtención del Premio Nacional de Arquitectura por parte de Lawner, merece ser revisitado.

Como ocurre en cada nueva edición de Revista de Arquitectura, los contenidos de este número esperan contribuir al debate disciplinar desde una mirada amplia, conscientes de que en ningún caso se trata de aproximaciones definitivas. Las formas de habitar que a continuación se exponen, son solo una parte, una parcialidad incompleta de una condición existencial en permanente transformación. 